\section{Out-of-season Prickly Pear: Fruit Characteristics and Effect of Fertilization and Short Droughts on Productivity}

\author{
Avinoam Nerd', Avraham Karady ${ }^{1}$, and Yosef Mizrahi ${ }^{1,2}$ \\ Ben-Gurion University of the Negev, P. O. Box 1025, Beer-Sheva 84110 , \\ Israel
}

Additional index words. floral bud production, irrigation, fertilization, drought, fruit ripening, fruit characteristics, Opuntia ficus-indica

\begin{abstract}
Field experiments were conducted to examine the effect of fertilization and short periods of drought on the out-of-season winter crop in prickly pear [Opuntia ficus-indica (L.) Mill.]. In addition, the winter and summer crops were compared regarding floral bud production and fruit characteristics. Under both continuous fertigation ( $N, P, K$ applied with the irrigation water) and continuous irrigation, the number of floral buds per plant was much lower in the winter than in the summer crop. Fertilization increased production of floral buds in both crops, but to a greater extent in the winter crop. The increase in floral bud production in fertilized plants was associated with an increase in $\mathrm{NO}_{3}-\mathrm{N}$ content in the cladodes. Suspension of fertigation for 4 or 8 weeks immediately after the summer harvest decreased cladode water content and delayed and reduced floral bud emergence as compared with continuous fertigation (control) or late drought ( 4 or 8 weeks) applied 4 weeks after the summer harvest. The plants subjected to early drought suffered from high mortality of floral buds. The fruits of the winter crop ripened in early spring, following the pattern of floral bud emergence the previous autumn. Mean fresh weight and peel : pulp ratio (w/w) were higher in fruits that ripened in the spring (winter crop) than in fruits that ripened in the summer.
\end{abstract}

Plantations of prickly pear in the Mediterranean region are not irrigated or are only slightly irrigated during fruit development and flower in the spring (Barbera, 1984; Portolano, 1969). An autumn period of flowering has been reported for prickly pear grown under irrigation in the Santa Clara Valley, Calif. (Curtis, 1977), and a similar phenomenon was observed recently in Israel in plantations irrigated in the late summer and in the autumn. Induction of flowering by applying irrigation after a short drought period has been reported for some tropical and subtropical trees, such as coffee and lemon (Magalhaes and Angelocci, 1976; Monselise, 1985; Southwick and Davenport, 1986). Therefore, we believed that irrigation followed by a drought period might induce autumn flowering in prickly pear.

Data concerning floral bud production and flowering in prickly pear are very scarce (Gibson and Nobel, 1986), but recently we

Received for publication 16 Mar. 1989. The use of trade or manufacturer's names in this paper is for the reader's information only and does not imply endorsement of any product or service by the USDA. The cost of publishing this paper was defrayed in part by the payment of page charges. Under postal regulations, this paper therefore must be hereby marked advertisement solely to indicate this fact. demonstrated that N-P-K fertilizer applied during the winter increased floral bud production in the spring, while use of plastic coverings in the early spring decreased it (Nerd et al., 1989).

The objectives of the experiments reported below were to: a) study the effect of fertilization and of short drought periods applied after the summer harvest on floral bud production in the autumn and on fruit ripening time and b) compare the fruit characteristics of the winter (out-of-season) crop with those of the summer crop.

The study was carried out in 1988 and 1989 on 'Ofer' prickly pear grown on sandy soil at Moshav Yevul in the Western Negev of Israel. Rainfall (winter only) totalled 130 and $160 \mathrm{~mm}$ for $1987-88$ and 1989-90, respectively. The plantation was established from cuttings planted in Sept. 1986 at $4 \times$

In Summer 1988, the height of the plants was $1.7 \mathrm{~m}$ and the fruit yield was $20 \mathrm{t} \cdot \mathrm{ha}^{-1}$. The plants had been drip-fertigated monthly with $30 \mathrm{~mm}$ of fertilizer solution in AprilSeptember and $15 \mathrm{~mm}$ in October-March for $\mathrm{P}_{2} \mathrm{O}_{5}\left(\mathrm{H}_{3} \mathrm{PO}_{4}\right)$, and $\mathrm{K}_{2} \mathrm{O}\left(\mathrm{KNO}_{3}\right)$ in the irrigation water of 70,30 , and $70 \mathrm{ppm}$, respectively. Experiment 1 started in Nov. 1987; the first phase, ending in Apr. 1988, was summarized in a previous report (Nerd et al., 1.5-m spacing. a concentration of $\mathrm{N}\left(\mathrm{NH}_{4} \mathrm{NO}_{3}+\mathrm{KNO}_{3}\right)$,
1989). It was designed to study effects of drought and fertilizer on floral bud production. Two of the treatments in this experiment were continued until Spring 1989: 1) continuous fertigation (control) and 2) continuous irrigation with fertilizer withdrawn from the irrigation water starting Nov. 1987. The experiment was a randomized block design, with six plants per treatment in each of three blocks. Floral buds were counted in each plant at the end of the autumn and spring flush. Sampling for nutrient analysis and determinations of $\mathrm{NO}_{3}-\mathrm{N}, \mathrm{P}$, and $\mathrm{K}$ content were described by Nerd et al. (1989).

In Expt. 2, plants of the continuous fertigation regime (as in Expt. 1) were subjected to varying periods of drought (interruption of fertigation) during Autumn 1988 to study the effect of drought on floral bud production and fruit ripening.

The treatments were: 1) control - continous fertigation; 2) and 3) interruption offertigation from $20 \mathrm{Aug}$. (the end of the summer harvest) for 4 or 8 weeks, respectively; and 4) and 5) interruption of fertigation from 20 Sept. for 4 and 8 weeks, respectively.

A randomized block design was used with five plants per treatment in each of four blocks. New floral buds were counted and tagged every 2 weeks. Floral buds that failed to develop flowers were counted in Jan. 1989, $\approx 2$ months after floral bud emergence had ceased; they remained small, eventually becoming dark and dry. Anthesis occurred 4 to 5 weeks after the initiation of viable floral buds.

Ripe fruits (pale-yellow skin) were harvested every 2 weeks, counted, and weighed. Batches of 15 ripe fruits were randomly sampled in mid-March (treatments 4 and 5), the beginning of April (treatment 1), and midApril (treatment 2). The peel and pulp were separated and weighed, seeds were counted, and total soluble solids concentration (TSS) in the pulp was determined by means of a hand-held refractometer. The same characteristics were recorded in summer (July) in the control plants.

Water content was determined in full-grown cladodes every 2 weeks. Two samples were taken from the upper parts of two cladodes in each of two plants per replication in the late afternoon with a cork borer $(12 \mathrm{~mm}$ in diameter) and weighed before and after ovendrying for 48 hat $70 \mathrm{C}$.

Drought and fertilizer (Expt. 1). Plants in both treatments developed floral buds in spring and in autumn, but significantly more floral buds were produced in spring than autumn (Table 1). The effect of fertilization was to increase the number of floral buds per plant and was more pronounced in autumn than in the spring.

The cladodes bearing the winter crop (formed in 1988) were sampled in Sept. 1988 for nutrient analysis. Fertilized plants had elevated $\mathrm{NO}_{3}-\mathrm{N}, \mathrm{P}$, and $\mathrm{K}$ levels as compared with nonfertilized plants; however, only 
Table 1. Effect of fertigation on the mean number of floral buds per plant and on $\mathrm{NO}_{3}-\mathrm{N}, \mathrm{P}$, and $\mathrm{K}$ concentrations of cladodes (Expt. 1). Floral buds emerged in Autumn 1988 (20 Aug.-15 Sept.) and in Spring 1989 (20 Mar.-30 Apr.). Cladode were sampled for nutrient analysis at the beginning of September and at the end of February, inception of floral budding.

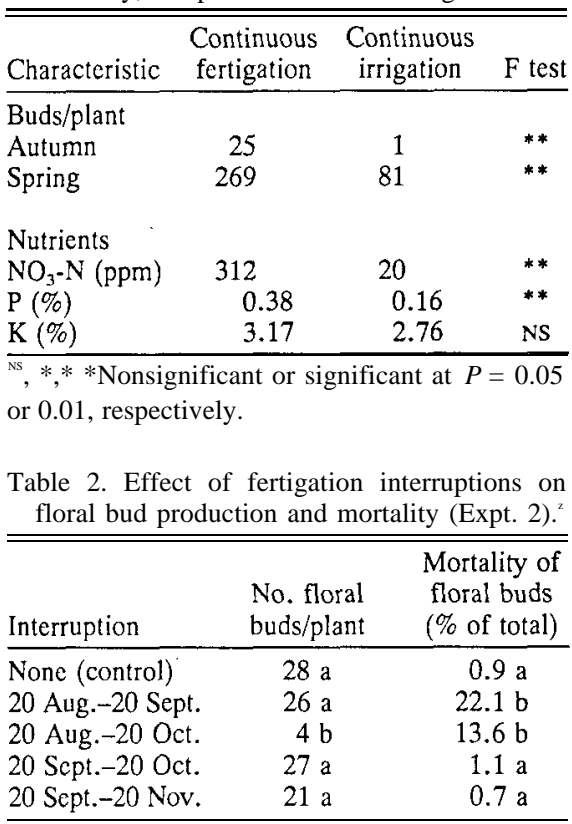

${ }^{2}$ Mean separation within columns by Duncan multiple range test, $P=0.05$.

Table 3. Characteristics (mean \pm SE) of fruits of winter crop (autumn flowering) and summer crop (spring flowering). Forty-five fruits were sampled in each season.

\begin{tabular}{lcc}
\hline \hline $\begin{array}{l}\text { Fruit } \\
\text { characteristics }\end{array}$ & $\begin{array}{c}\text { Winter } \\
\text { crop }\end{array}$ & $\begin{array}{c}\text { Summer } \\
\text { crop }\end{array}$ \\
\hline $\begin{array}{l}\text { Fresh weight }(\mathrm{g}) \\
\text { Peel weight }(\mathrm{g})\end{array}$ & $178 \pm 4.6$ & $116 \pm 4.7$ \\
Pulp wcight $(\mathrm{g})$ & $76 \pm 2.1$ & $57 \pm 2.1$ \\
Peel : pulp ratio & $1.34 \pm 0.06$ & $0.92 \pm 2.2$ \\
TSS (\%) & $11.8 \pm 1.2$ & $12.8 \pm 0.03$ \\
No. of seeds & $129 \pm 12$ & $121 \pm 6$ \\
\hline
\end{tabular}

the differences in $\mathrm{NO}_{3}-\mathrm{N}$ and $\mathrm{P}$ were statistically significant (Table 1). These results are in contrast to the first phase nutrient analysis in Spring 1988, where $\mathrm{NO}_{3}-\mathrm{N}$ and $\mathrm{K}$ were significantly higher in the fertigated plants and the latter produced more floral buds than the nonfertilized plants (Nerd et al., 1989). Increased levels of $\mathrm{N}$ may have stimulated floral budding. This result contradicts the common belief that $\mathrm{N}$ stimulates vegetative growth and inhibits reproductive growth. However, it is also possible that either the level of $\mathrm{P}$ or $\mathrm{K}$ or the interaction between all these elements plays the determinant role in floral bud production; only specifically designed experiments can settle this point. The tendency to develop more floral buds in spring than in autumn indicates that certain environmental conditions in winter stimulate extensive floral bud production, probably low winter temperatures (Nerd et al., 1989) and/ or the increase in photoperiod from winter to spring.

Period of drought (Expt. 2). The water

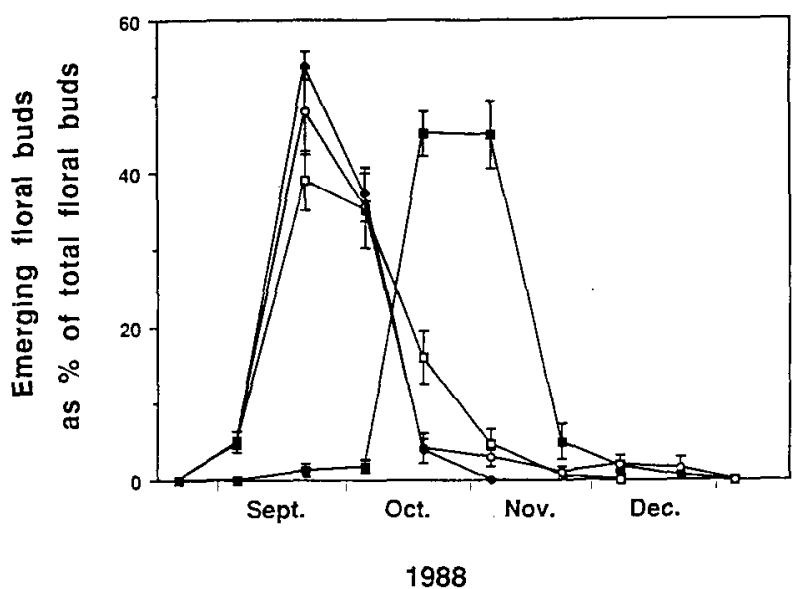

Fig. 1. Effect of fertigation regimes on the time of floral bud emergence. ( $\square$ ) Continuous fertigation; interruption of fertigation: ( $\square$ ) 20 Aug.-20 Sept., ( ○ ) 20 Sept.-20 Oct., ( $\bullet$ ) 20 Sept.-20 Nov. (Expt. 2). Vertical lines represent SE. Treatment 3-interruption of fertigation from 20 Aug.-20 Oct.-is omitted; see text.

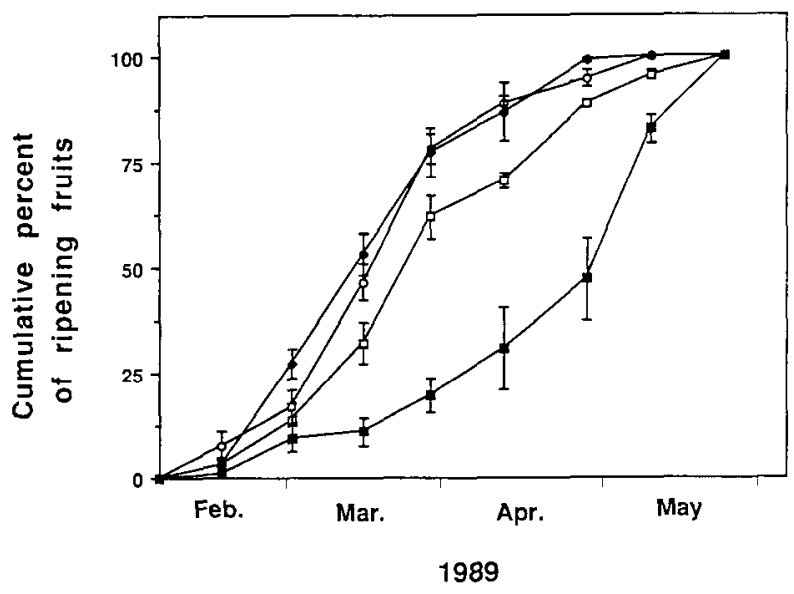

Fig. 2. Cumulative percentage of fruits ripened during the spring in plants subjected to various fertigation regimes. ( $\square$ ) Continuous fertigation; interruption of fertigation: ( $\square$ ) 20 Aug.-20 Sept., ( $\bigcirc$ ) 20 Sept.-20 Oct., ( $\bullet$ ) 20 Sept.-20 Nov. (Expt. 2). Vertical lines represent SE. Treatment 3: as in Fig. 1.

content of cladodes was taken as a measure of plant water status where fertigation was interrupted for various periods in August and September. It remained stable (94\% of fresh weight) from September through December in the control plants and in treatments 4 and 5 (interruption of fertigation after 20 Sept.). However, water content dropped more than $1.5 \%$ in September and October in plants from which fertigation was withheld starting 20 Aug.; when fertigation was resumed, the water content in these plants increased to the control level after 2 weeks. The consistently high water content in cladodes of plants subjected to drought late in the season could be attributed to reduced evapotranspiration from October onward as air temperatures dropped and humidity rose.

Production of autumn floral buds was affected by the fertigation interruptions. The group of plants subjected to an 8-week drought immediately after the summer harvest $(20$ Aug.) produced significantly fewer floral buds per plant than the other treatments (Table 2). Floral bud emergence in this group occurred during October and November and was very sporadic (data not shown), while in each of the other treatments (Fig. 1), a concentrated flush of floral budding was recorded. The peak of floral bud emergence in plants subjected to drought for 4 weeks beginning 20 Aug. occurred at the end of October, $\approx 4$ weeks later than in continuously fertigated plants or in the two groups subjected to drought from 20 Sept. (Fig. 1). Mortality of floral bud was significant ( $14 \%$ to $22 \%$ of total) in plants dried from 20 Aug. but negligible in the other treatments (Table 2).

Thus, application of a short drought period (4 weeks) directly after the summer harvest depressed cladode water content, delayed floral bud emergence, but did not affect floral bud production; when prolonged to 8 weeks (treatment 3), cessation of fertigation directly after harvest inhibited and delayed floral bud production. Besides drought, low temperatures also may have played a role in inhibiting floral bud production in the plants of treatment 3 , since termination of the drought coincided with cooler temperatures (average temperatures in September, October, and November were 31,27 , and 22C, 
respectively). Because the only plants to suffer a high percentage of floral bud mortality were those that developed floral buds late in the season, the November drop in temperature and frosts recorded in this season may be assumed to be harmful to floral buds. Plants of the other treatments were at the stage of flowering or fruit set in November, both of which are apparently less sensitive to low temperatures. Since floral production did not increase when the drought period was terminated before the onset of lower temperatures (treatment 2), it appears that floral bud production in 'Ofer' prickly pear is not stimulated by short-term drought. Examination of the response of prickly pear to water stress more severe than that applied in our experiment is needed to clarify the effect on floral bud induction.

Fruits from the autumn flush of floral budding ripened during the following spring (Fig. 2). (Treatment 3 of Expt. 2 is not considered here.) Time to maturity was directly related to the floral budding time. About $50 \%$ of the fruit ripened by the end of March in plants of the early flush and by the beginning of May in plants of the late flush. Ripened fruits of each group were sampled at the stage when skin was pale yellow. No significant differences were found among the groups in mean fresh weight, peel : pulp ratio, TSS, or number of seeds (data not shown). Thus, when fruits of the winter crop were compared with those of the previous summer crop (regular fertigation regime), the values of each attribute for all treatments of Expt. 2 were combined. The mean fresh weight of the spring fruits (winter crop) was 1.5 -fold higher than that of the summer fruits (Table 3 ). This corresponded to an increase in pulp and especially in peel weight, since the peel : pulp ratio was higher in the winter than in the summer fruits.

The winter crop produced heavier fruits than in the spring, possibly due to the lower number of fruits per plant, which was about one-tenth of that in the spring. However, since the ratio of peel to pulp weight was high, it is possible that fruit weight was also affected by the conditions prevailing when the fruits developed, such as high relative humidity and low temperatures.

According to the experience of Y. EinGedi (personal communication), who was involved in our study, the poor yield of the autumn flush of floral buds $\left(\approx 5 \mathrm{t} \cdot \mathrm{ha}^{-1}\right)$ was not reflected in low profitability compared with the regular crop $\left(\approx 30 \mathrm{t} \cdot \mathrm{ha}^{-1}\right)$, because fruits marketed in the spring had 5-fold higher prices than the summer crop and involved lower thinning, harvest, and transport expenditures.

The results of this study indicate that fertigation increases productivity in prickly pear in general and especially in the out-of-season crop, which is much smaller than the regular crop and whose floral bud production is more dependent on fertilization. Since the termination of our study, six prickly pear growers in Israel have adopted our fertigation scheme (continuous fertigation); all obtained an additional winter crop, in conformity with our results.

\section{Literature Cited}

Barbera, G. 1984. Ricerche sull'irrigazione del ficodinia. Riv. Fruticultura Ortofloricultura 46:49-55.

Curtis, J.R. 1977. Prickly pear fanning in the Santa Clara Valley, California. Econ. Bet. 31:175179.

Gibson A.W.C. and P.S. Nobel. 1986. The cactus primer. Harvard University Press, Cambridge, Mass.

Magalhaes, A.C. and L.R. Angelocci. 1976. Sudden alteration in water balance associated with flower bud opening in coffee plants. J. Hort. Sci. 51:419-423.
Monselise, S.P. 1985. Citrus and related genera, p. 275-294. In: A.H. Halevy (ed.). CRC handbook of flowering. vol. H. CRC Press, Boca Raton, Fla.

Nerd A., A. Karadi, and Y. Mizrahi. 1989. Irrigation, fertilization and polyethylene covers in prickly pear influence bud development. HortScience 24:773-775.

Portolano, N. 1969.11 fico d'india. Edizioni Agricole, Bologna.

Southwick, S.M. and T.L. Davenport. 1986. Characterization of water stress and low temperature effects on flower induction in citrus. Plant Physiol. 81:26-29. 